\title{
Return to work after cancer treatment of gynecologic cancer in Japan
}

\author{
Keiichiro Nakamura*, Hisashi Masuyama, Takeshi Nishida, Junko Haraga, Naoyuki Ida, Masayuki Saijo, \\ Tomoko Haruma, Tomoyuki Kusumoto, Noriko Seki and Yuji Hiramatsu
}

\begin{abstract}
Background: Gynecologic cancer is one of the most common malignant diseases in working-age women. This study investigated whether several characteristics influence return to work after treatment of gynecologic cancer.

Methods: We investigated the correlations between return to work and several other characteristics in 199 gynecologic cancer survivors. Questionnaires were distributed to patients with cancer $(\geq 1$ year after treatment and age of $<65$ years) who visited Okayama University. Logistic regression analysis and receiver operating characteristic curves were used to determine whether each characteristic influenced return to work (no return to work or job change) in these gynecologic cancer survivors.

Results: For all patients, the mean age at the time of diagnosis was 47.0 years, and the average number of years after treatment was 4.5. Forty-four patients (53.7\%) who were non-regular employees continued to be employed at the same workplace. Non-regular employment had a significantly higher area under the curve (AUC) (0.726) than other characteristics in terms of negatively affecting return to work. Additionally, non-regular employment tended to have a higher AUC (0.618) than other characteristics in terms of job changes.
\end{abstract}

Conclusions: Non-regular employment was the variable most likely to negatively affect return to work and job changes in employed patients who underwent treatment for gynecologic cancer.

Keywords: Return to work, Job change, Gynecologic cancer survivors

\section{Background}

The incidence of gynecologic malignancy has increased in recent years in Japan, with an estimated 30,964 newly diagnosed patients in 2009 [1]. The Japan Society of Obstetrics and Gynecology reported that about $70 \%$ of all patients diagnosed with cancer in Japan were of working age (20-64 years old) [2]. Gynecologic cancer is one of the most common malignant diseases in working-age women, and improvements in the management of gynecologic cancer have increased the survival rate in patients with this disease. Several studies have reported that an average of 60 to $67 \%$ of patients who had worked before their cancer diagnosis returned to work after the initial treatments [3-7]. However, the patients with cancer for whom return to work was

\footnotetext{
* Correspondence: k-nakamu@cc.okayama-u.ac.jp Department of Obstetrics and Gynecology, Okayama University Graduate School of Medicine, Dentistry and Pharmaceutical Sciences, 2-5-1 Shikata-cho, Kita-ku, Okayama 700-8558, Japan
}

investigated and validated included few patients with gynecologic cancer; thus, the applicability of such an investigation of these patients has not been established. This study aimed to clarify the status of return to work among gynecologic cancer survivors.

\section{Methods \\ Study population}

Questionnaires were distributed to gynecologic cancer survivors ( $\geq 1$ year after treatment and age of $<65$ years) who visited Okayama University for consultation from 28 May 2015 to 28 December 2015. All patients were informed about the survey by their consultant doctors and provided written informed consent to participate in this study. All answers were voluntary. Completed questionnaires were collected using in-hospital collection boxes. This study protocol was approved by the Institutional Review Board of Okayama University Hospital (No. 1504-001). The dataset comprised responses from 
Table 1 Questionnaires for gynecologic cancer survivors

\begin{tabular}{|c|c|c|c|c|c|c|}
\hline Did you have employment at the time of diagnosis? & 1. Yes & 2. No & & & & \\
\hline What kind of work at the time of diagnosis did you do? & 1. Self-employed & 2. Publicly employed & 3. Regularly employed & 4. Non-regularly employed & & \\
\hline $\begin{array}{l}\text { How many days did you work per week at the time of } \\
\text { diagnosis? }\end{array}$ & 1. 1 day/week & 2. 2 day/week & 3. 3 day/week & 4. 4 day/week & 5.5 day/week & 6. $\geq 6$ day/week \\
\hline $\begin{array}{l}\text { How many hours did you work per day at the time of } \\
\text { diagnosis? }\end{array}$ & 1. $<3 \mathrm{~h} /$ day & 2. $3-5$ h/day & 5. 6-8 h/day & 6. $>8$ h/day & & \\
\hline $\begin{array}{l}\text { How many people did you work in workplace at the } \\
\text { time of diagnosis? }\end{array}$ & 1. $\leq 5$ peoples & 2. 6-10 peoples & 3. 11-20 peoples & 4. $21-30$ peoples & 5. 31-50 peoples & 6. $>50$ peoples \\
\hline $\begin{array}{l}\text { How much did you have income ( } 10,000 \text { yen) at the } \\
\text { time of diagnosis? }\end{array}$ & 1. $<103$ & 2. $103-149$ & 3. $150-299$ & 4. $300-499$ & 5. $\geq 500$ & \\
\hline $\begin{array}{l}\text { How much did you have household income (10,000 yen) } \\
\text { at the time of diagnosis? }\end{array}$ & 1. $<300$ & 2. 300-499 & 3. 500-699 & 4. $700-999$ & 5. 1,000-1,499 & 6. $\geq 1,500$ \\
\hline Did you have return to work after treatment? & 1. Same reinstatement & 2. Job change & 3. No return to work & & & \\
\hline $\begin{array}{l}\text { What kind of employment at the job change after } \\
\text { treatment? }\end{array}$ & 1. Self-employed & 2. Publicly employed & 3. Regularly employed & 4. Non-regularly employed & & \\
\hline How many days did you return to work after treatment? & 1. $<1$ months & 2. $1-3$ months & 3. 4-6 months & 4. 7-12 months & 5. $>12$ months & \\
\hline Did you change in the working hours after treatment? & 1. Increase & 2. Decrease & 3. No change & & & \\
\hline Did you change person income after treatment? & 1. Increase & 2. Decrease & 3. No change & & & \\
\hline $\begin{array}{l}\text { What did you feel uneasiness after treatment? (Multiple } \\
\text { answers allowed) }\end{array}$ & 1. Physical uneasiness & 2. Psychological uneasiness & & & & \\
\hline
\end{tabular}


199 gynecologic cancer survivors who were employed and working at the time of their cancer diagnosis. Table 1 shows the distribution of the questionnaires with gynecologic cancer survivors (type of employments, work days per week, work time per day, number of people at workplace, personal income, household income, return to work, the work day per week after treatment, the working hours after treatment, person income after treatment, physical and psychological uneasiness after treatment).

\section{Study variables}

The type of employment at diagnosis was categorized according to the patients' responses as follows: selfemployed, publicly employed (teacher, dietician, care person), regularly employed (permanently employed), or non-regularly employed (part-time workers, temporary workers, contract-based workers, and dispatched workers). The patients also provided information on the following characteristics: age, marital status, children or no children, cancer site, cancer stage, treatment duration, employment pattern, work days per week, work time per day, number of people at workplace, personal income, household income, physical uneasiness, psychological uneasiness, and return to work (no return to work or change in job). Finally, we examined the correlations between job changes and reinstatement time and between work time and personal income.

\section{Statistical analysis}

Statistical analyses were performed using the MannWhitney $U$-test. A receiver operating characteristic (ROC) curve was generated, and the area under the curve (AUC) was calculated to evaluate the discriminatory ability of each scoring system. We also examined the data in crosstabulated form to explore return to work (no return to work or change in job). Analyses were performed using SPSS software, version 20.0 (IBM Corp., Armonk, NY USA). A $P$ value of $<0.05$ was considered statistically significant.

\section{Results}

A total of 265 gynecologic cancer survivors responded to the questionnaires at the time of diagnosis. At diagnosis, 199 patients were employment, and 66 patients were non-employment. 199 gynecologic cancer survivors who were employed and working at the time of their cancer diagnosis' characteristics are summarized in Table 2. The mean age at the time of diagnosis was 47.0 years (median, $46.4 \pm 9.8$ years; range, 25-64 years), and the average number of years after treatment was 4.5. A total of 144 patients $(72.4 \%)$ were married, and 138 patients $(69.3 \%)$ had children. The diagnoses were cervical cancer $(n=105$, $52.8 \%)$, endometrial cancer $(n=64,32.2 \%)$, and ovarian
Table 2 Patient characteristics

\begin{tabular}{|c|c|c|}
\hline Age at diagnosis & $\begin{array}{l}\text { Median, } 46.4 \\
\text { Numbers }\end{array}$ & $\begin{array}{l}\text { Range, 25-64 } \\
(\%)\end{array}$ \\
\hline \multicolumn{3}{|l|}{ Marry } \\
\hline Yes & 144 & 72.4 \\
\hline No & 55 & 27.6 \\
\hline \multicolumn{3}{|l|}{ Children } \\
\hline Yes & 138 & 69.3 \\
\hline No & 61 & 30.7 \\
\hline \multicolumn{3}{|l|}{ Cancer site } \\
\hline Cervical cancer & 105 & 52.8 \\
\hline Endometrial cancer & 64 & 32.2 \\
\hline Ovarian cancer & 30 & 15 \\
\hline \multicolumn{3}{|l|}{ Stage } \\
\hline Early & 170 & 85.4 \\
\hline Advanced & 29 & 14.6 \\
\hline \multicolumn{3}{|l|}{ Treatment } \\
\hline Surgery & 85 & 42.7 \\
\hline Surgery + Chemotherpy & 50 & 25.1 \\
\hline Surgery + Radiation (included CCRT) & 37 & 18.6 \\
\hline Radiation (included CCRT) & 27 & 13.6 \\
\hline \multicolumn{3}{|l|}{ Employment pattern } \\
\hline Self-employed & 31 & 15.6 \\
\hline Publicly employed & 18 & 9 \\
\hline Regularly employed & 68 & 34.2 \\
\hline Non-regularly employed & 82 & 41.2 \\
\hline
\end{tabular}

CCRT concurrent chemoradiotherapy

cancer $(n=30,15.0 \%)$. More patients had early-stage cancer $(n=170,85.4 \%)$ than advanced-stage cancer $(n=29$, $14.6 \%)$. A high percentage of patients had undergone only surgery ( $n=85,42.7 \%)$; fewer patients had undergone surgery and chemotherapy $(n=50,25.1 \%)$, surgery and radiation with/without concurrent chemotherapy $(n=37$, $18.6 \%)$, and radiation therapy with/without concurrent chemotherapy $(n=27,13.6 \%)$. At diagnosis, 82 patients (41.2\%) were non-regularly employed, 68 (34.2\%) were regularly employed, 31 (15.6\%) were self-employed, and 18 (9.0\%) were publicly employed.

In this study, 32 patients $(16.1 \%)$ did not return to work and 25 patients $(12.6 \%)$ changed their job. These patients were investigated in terms of their relationship with each employment pattern. Patients who did not return to work (including because their business closed) were distributed as follows: self-employed $(n=3,9.7 \%)$, regularly employed $(n=4,5.9 \%)$, and non-regularly employed $(n=25,30.5 \%)$. Patients who changed their jobs were distributed as follows: publicly employed $(n=2$, $11.1 \%)$, regularly employed $(n=10,14.7 \%)$, and nonregularly employed $(n=13,15.9 \%)$. Interestingly, of the 
patients who were able to return to the same workplace, 28 (90.3\%) were self-employed, 16 (88.9\%) were publicly employed, 54 (79.4\%) were regularly employed, and 44 (53.7 \%) were non-regularly employed (Fig. 1).

We investigated correlations among each characteristic; i.e., age, marital status, children, cancer site, cancer stage, treatment duration, employment pattern, work days per week, work time per day, number of people at workplace, personal income, household income, physical uneasiness, psychological uneasiness, and no return to work or job change. We used ROC curve analyses to predict no return to work or job change. Non-regularly employed patients had a significantly higher AUC (0.726) than did other characteristics in terms of negatively affecting return to work. Additionally, non-regular employment tended to have a higher AUC (0.618) than did other characteristics in terms of job change. Moreover, personal income had a significantly high AUC (0.648) in terms of negatively affecting return to work (Fig. 2 and Table 3).

To examine the correlations of employed workplace (same workplace/job change) and employment (non-regular employment/self-, public, and regular employment) with the reinstatement time, work time, and personal income, we divided return to work (including a job change) after treatment into four groups: Group 1, same workplace plus self-, public, or regular employment $(n=$ 94); Group 2, job change plus self-, public, or regular employment $(n=11)$; Group 3, same workplace plus non-regular employment $(n=38)$; and Group 4, job change plus non-regular employment $(n=14)$. The percentage of patients with a $>6$-month reinstatement was significantly higher in Group 2 than Group $1(p<$ 0.001 ) and was significantly higher in Group 4 than in Group $3(p<0.001)$. The percentage of reduced work time was significantly higher in Group 2 than in Group $1(p<$ $0.05)$ and was significantly higher in Group 4 than in Group $3(p<0.05)$. There was a significant difference in the percentage of reduced personal income between Groups 2 and $1(p<0.001)$ and between Group 4 and Group 3 ( $p<0.05$, respectively) (Fig. 3 ).

\section{Discussion}

Cancer treatment options are improving, and the number of cancer survivors thus continues to grow. Returning to

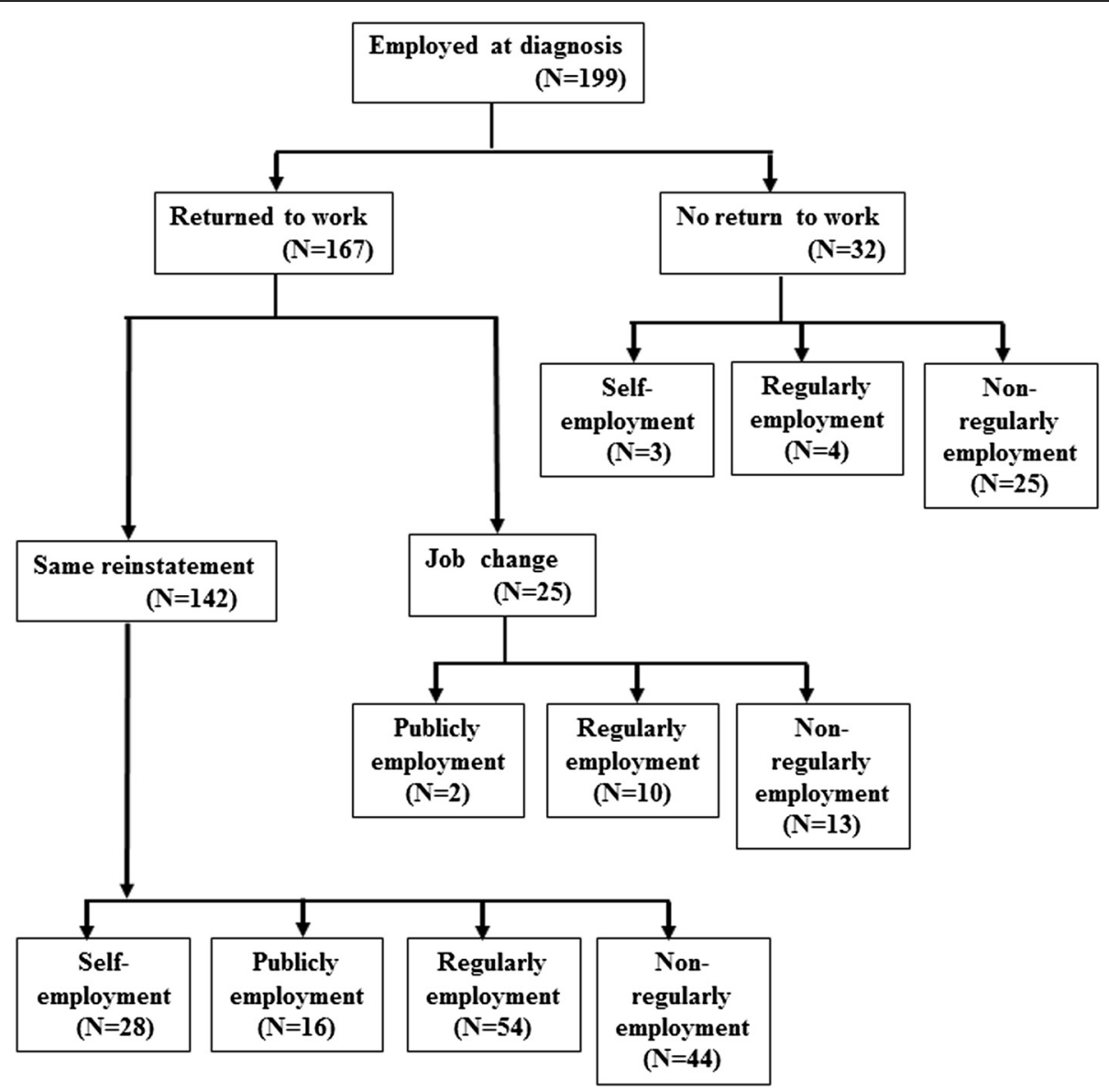

Fig. 1 A total of 199 patients with gynecologic cancer were working at the time of cancer diagnosis 

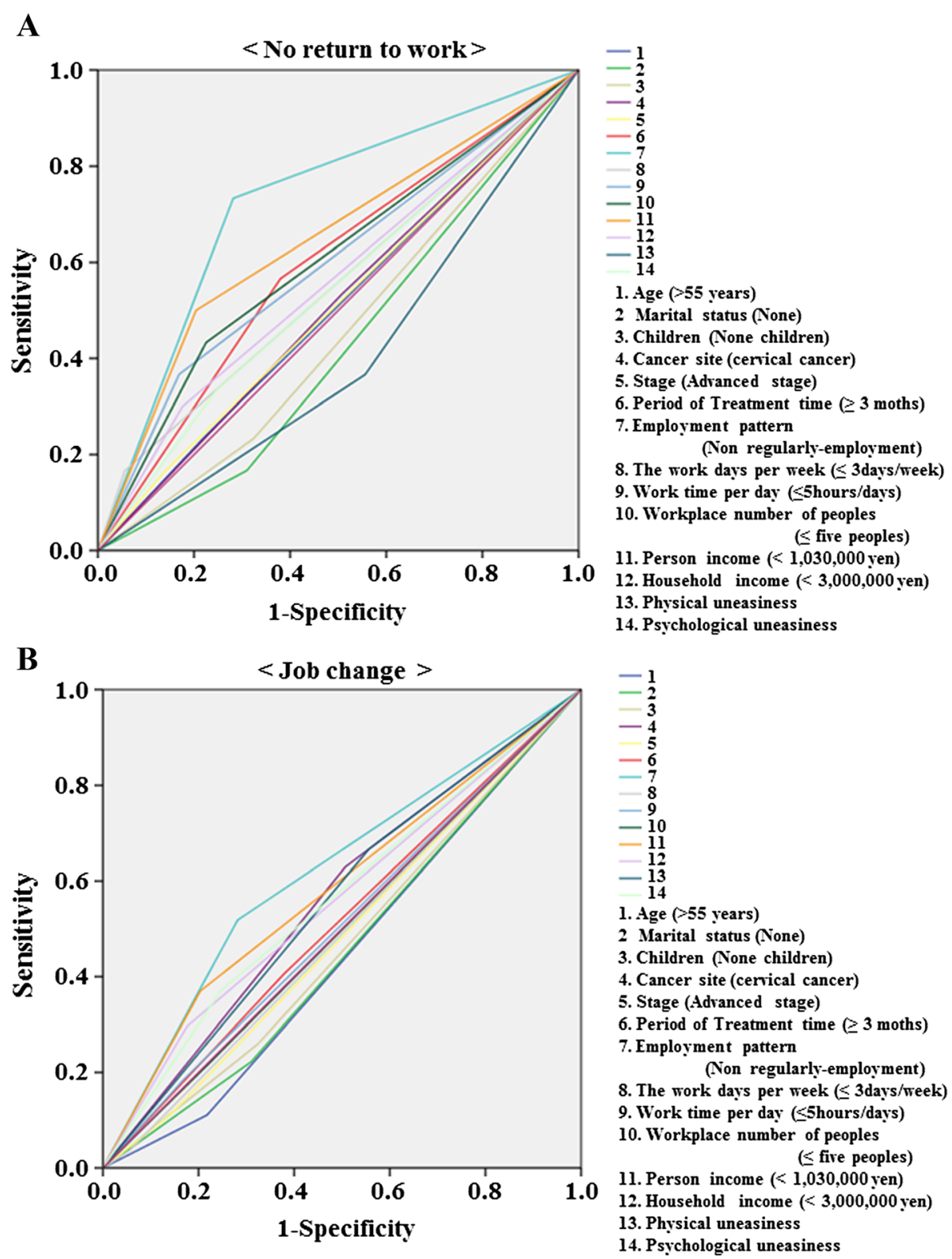

Fig. 2 Receiver operating characteristic curve analyses to predict no return to work or job change. a No return to work (same reinstatement $(n=142)$ vs no return to work $(n=32))$. b Job change (same reinstatement $(n=142)$ vs job change $(n=25))$. Correlations among all characteristics: 1 . Age, 2. Marital status, 3. Children, 4. Cancer site, 5. Cancer stage, 6. Treatment duration, 7. Employment pattern, 8. Work days per week, 9. Work time per day, 10. Number of people at workplace, 11. Personal income, 12. Household income, 13. Physical uneasiness, and 14. Psychological uneasiness

work after treatment is important for the patient's quality of life, financial security, restoration of a stable social environment, and the feeling of normality in both patients and their family. Returning to work can improve the quality of life of cancer survivors, and could be a symbol of recovery and return to a normal life $[5,8]$. Returning to work may help patients overcome the negative impacts of disease treatments, has a positive financial outcome for patients, and reduces the economic burden of cancer on society $[9,10]$. Many cancer survivors are able to return to work [11-13], but are likely to encounter significant difficulties as a result of reduced working hours, fatigue, and exhaustion [3, 14-18]. In a systematic review, Spelten et al. [5] evaluated 14 studies published from 1985 to 1999 and found that $62 \%$ (range, 30-93\%) of cancer survivors had returned to work. Similarly, Mehnert et al. [13] evaluated 64 studies published from 2000 to 2009 and found that $62 \%$ (range, 24-94\%) of cancer survivors had returned to work. Several studies reported that an average of 60 to $67 \%$ of patients who had worked before their 
Table 3 Comparison of AUC for no return to work and job change

\begin{tabular}{|c|c|c|c|}
\hline \multicolumn{4}{|c|}{ A. Not returned to work (Same reinstatement $(N=142)$ vs Not returned to work $(N=32))$} \\
\hline Period & AUC & $95 \% \mathrm{Cl}$ & $P$-value \\
\hline Age ( $>55$ years) & 0.508 & $0.393-0.622$ & 0.897 \\
\hline Marital status (None) & 0.428 & $0.321-0.536$ & 0.218 \\
\hline Children (None children) & 0.455 & $0.344-0.565$ & 0.436 \\
\hline Cancer site (Cervical cancer) & 0.513 & $0.399-0.627$ & 0.821 \\
\hline Stage (Advanced stage) & 0.513 & $0.398-0.628$ & 0.824 \\
\hline Period of Treatment time ( $\geq 3$ moths) & 0.593 & $0.480-0.706$ & 0.109 \\
\hline Employment pattern (Non regularly-employment) & 0.726 & $0.625-0.827$ & $<0.001^{*}$ \\
\hline The work days per week ( $\leq 3$ days/week) & 0.555 & $0.436-0.675$ & 0.343 \\
\hline Work time per day ( $\leq 5 \mathrm{~h} /$ days) & 0.599 & $0.480-0.717$ & 0.089 \\
\hline Workplace number of peoples ( $\leq$ Five peoples) & 0.604 & $0.487-0.721$ & 0.074 \\
\hline Person income $(<1,030,000$ yen) & 0.648 & $0.532-0.763$ & $0.011^{*}$ \\
\hline Household income (<3,000,000 yen) & 0.562 & $0.444-0.680$ & 0.287 \\
\hline Physical uneasiness & 0.405 & $0.294-0.516$ & 0.103 \\
\hline Psychological uneasiness & 0.543 & $0.427-0.660$ & 0.455 \\
\hline \multicolumn{4}{|c|}{ B. Job change (same reinstatement ( $n=142)$ vs job change $(n=25)$ ) } \\
\hline Period & AUC & $95 \% \mathrm{Cl}$ & $P$-value \\
\hline \multirow[t]{2}{*}{ Age (>55 years) } & 0.446 & $0.334-0.559$ & 0.378 \\
\hline & 0.456 & $0.341-0.571$ & 0.471 \\
\hline Children (None children) & 0.468 & $0.351-0.584$ & 0.595 \\
\hline Cancer site (Cervical cancer) & 0.561 & $0.444-0.678$ & 0.313 \\
\hline Stage (Advanced stage) & 0.485 & $0.368-0.602$ & 0.807 \\
\hline Period of Treatment time ( $\geq 3$ moths) & 0.514 & $0.394-0.633$ & 0.823 \\
\hline Employment pattern (Non regularly-employment) & 0.618 & $0.499-0.738$ & 0.051 \\
\hline The work days per week ( $\leq 3$ days/week) & 0.49 & $0.373-0.608$ & 0.874 \\
\hline Work time per day ( $\leq 5 \mathrm{~h} /$ days $)$ & 0.508 & $0.388-0.628$ & 0.894 \\
\hline Workplace number of peoples ( $\leq$ Five peoples) & 0.498 & $0.379-0.617$ & 0.979 \\
\hline Person income $(<1,030,000$ yen $)$ & 0.583 & $0.460-0.706$ & 0.172 \\
\hline Household income $(<3,000,000$ yen $)$ & 0.56 & $0.437-0.683$ & 0.323 \\
\hline Physical uneasiness & 0.555 & $0.439-0.672$ & 0.364 \\
\hline Psychological uneasiness & 0.562 & $0.440-0.684$ & 0.308 \\
\hline
\end{tabular}

AUC area under the curve ${ }^{*} p<0.05$

cancer diagnosis returned to work after the initial treatments [3-7]. In Japan, Ito et al. [19] reported that $75.8 \%$ of cancer survivors had returned to work. The present study thus aimed to clarify the status of returning to work among gynecologic cancer survivors. A high proportion of patients $(71.3 \%)$ in this study returned to work at the same workplace. Furthermore, 83.9 \% of gynecologic cancer survivors who had worked before their cancer diagnosis returned to work, included those who experienced a job change after treatment. The findings of this study are consistent with the results obtained for patients with other diseases and confirm that a significant percentage of survivors quit working for cancer-related reasons.

In this study, $16.1 \%$ of patients did not return to work, and $12.6 \%$ patients changed their job. We investigated the employment patterns and status of returning to work in patients with gynecologic cancer. No return to work (including because the business closed) occurred in $9.7 \%$ of self-employed patients, $5.9 \%$ of regularly employed patients, and $30.5 \%$ of non-regularly employed patients. Those who changed their jobs constituted $11.1 \%$ 


\section{A <More than 6months reinstatement $>$}

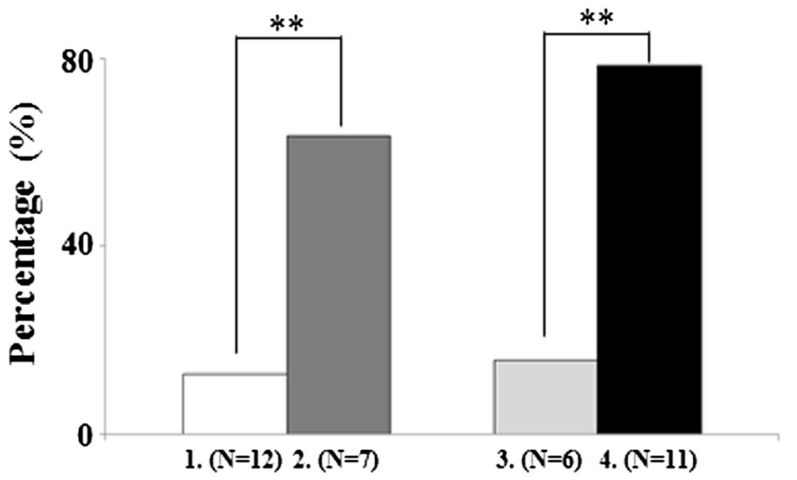

B $\quad<$ Reduced work time $>$

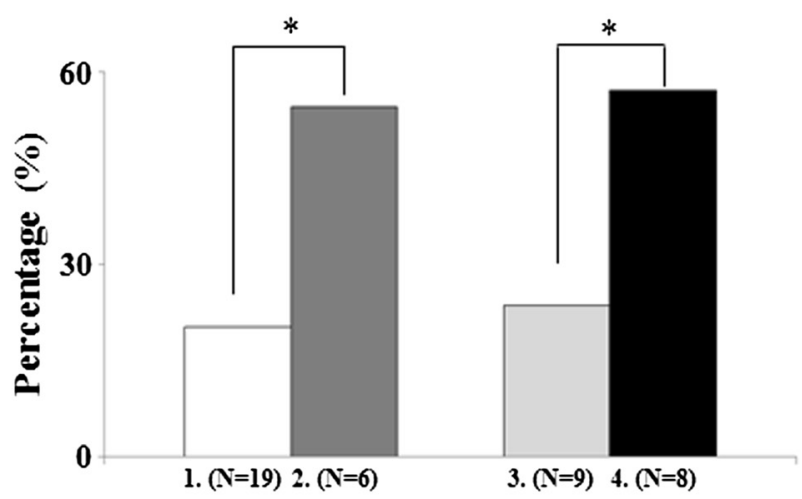

C $\quad<$ Reduced person income $>$

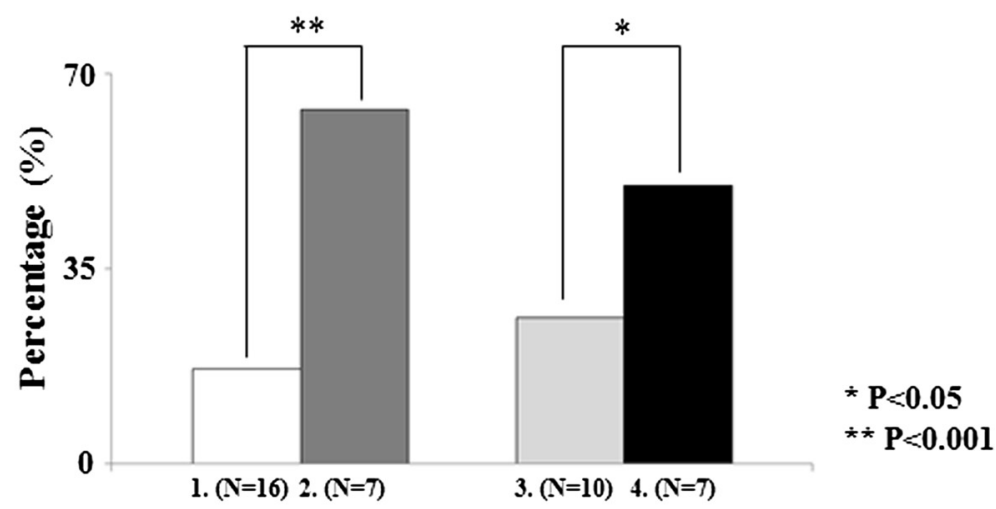

1. Same workplace + Self-, Publicly-,Regularly-Employments (n=94)

2. Change the job + Self-, Publicly-,Regularly-Employments (n=ll)

3. Same workplace + Non Regularly-Employments $(n=38)$

4. Change the job + Non Regularly-Employments $(n=14)$

Fig. 3 Correlation of employed workplace and employment with post-treatment reinstatement time, work time, and personal income. a More than $>6$ months reinstatement after treatment. $\mathbf{b}$ Reduced work time after treatment. c Reduced personal income after treatment. 1. Same workplace plus self-, public, or regular employment $(n=94)$. 2. Job change plus self-, public, or regular employment $(n=11) .3$. Same workplace plus non-regular employment $(n=38)$. 4. Job change plus non-regular employment $(n=14)$

of publicly employed patients, $14.7 \%$ of regularly employed patients, and $15.9 \%$ of non-regularly employed patients. Furthermore, among patients who were able to return to the same workplace, $90.3 \%$ were self-employed, $88.9 \%$ were publicly employed, $79.4 \%$ were regularly employed, and $53.7 \%$ were non-regularly employed. 
In patients with breast cancer, returning to work is associated with several risk factors such as sociodemographic factors, disease-related factors, treatment-related factors, psychological factors, and work-related factors [20]. We investigated the correlations between each characteristic and no return to work or job change. Our results showed that non-regular employment was the variable most likely to negatively affect return to work and job change. Interestingly, the findings of this study confirm that a significant percentage of survivors quit working for reasons related to their employment pattern. Among all employment patterns (non-regular, self-, public, and regular employment), significantly more patients experienced job changes than returned to work at the same workplace on the $>6$ months reinstatement after treatment. Among all employment patterns, significantly fewer patients changed jobs than returned to work at the same workplace on work times and personal income after treatment. The findings of this study confirm that change the job patients were significant high percentage of survivors extended reinstatement or considerably reduced their work hours and income.

We acknowledge that our study has some limitations. The number of patients was relatively small, and the examination was performed at a single facility. Further prospective studies involving more patients and facilities would provide more definitive data with which to clarify the significance of our findings.

\section{Conclusions}

Gynecologic cancer is one of the most common malignant diseases in working-age women. This study has revealed the status of returning to work in patients with gynecologic cancer. The present findings suggest that non-regular employment was the variable most likely to negatively affect return to work and job change in gynecologic cancer survivors. A high proportion of patients $(71.3 \%)$ in this study returned to work at the same workplace. However, $53.7 \%$ of non-regularly employed patients continued to be employed at the same workplace. Non-regular employment was the variable most likely to negatively affect return to work and job change. Prevention of not returning to work and changing jobs may be one of the most important factors for positive relationships with the patient, employer, and society. Social support should be established to ensure satisfactory return to work.

\section{Abbreviations}

$A \cup C$, area under the curve; ROC, receiver operating characteristic

\section{Acknowledgements}

The authors thank the study participants in each of the individual studies for their involvement.

\section{Funding}

This study was supported by Japanese Ministry of Education, Culture, Sports, Science, and Technology; grant no: 25482595 and 16K11141.

Availability of data and materials

Currently not applicable.

Authors' contributions

KN designed the study and performed the laboratory work, data collection, data management, statistical analysis, data interpretation, and manuscript writing. $\mathrm{HM}, \mathrm{TN}, \mathrm{JH}, \mathrm{NI}, \mathrm{MS}, \mathrm{TH}, \mathrm{TK}, \mathrm{NS}$, and $\mathrm{YH}$ participated in the study design and coordination and helped to draft the manuscript. All authors read and approved the final manuscript.

\section{Authors' information}

There is no additional information to disclose.

\section{Competing interests}

The authors declare that they have no competing interests.

Consent for publication

Not applicable.

\section{Ethics approval and consent to participate}

All patients provided informed written consent, and approval for this study was granted bythe Institutional Review Board of Okayama University Hospital (No. 1504-001).

Received: 22 January 2016 Accepted: 26 July 2016

Published online: 29 July 2016

References

1. Hori M, Matsuda T, Shibata A, Katanoda K, Sobue T, Nishimoto H, Japan Cancer Surveillance Research Group. Cancer incidence and incidence rates in Japan in 2009: a study of 32 population-based cancer registries for the Monitoring of Cancer Incidence in Japan (MCIJ) project. Jpn J Clin Oncol. 2015;45:884-91.

2. Katabuchi $\mathrm{H}$, Japanese gynecological cancer committee. Annual Report of Oncology Committee of Japan Society of Obstetrics and Gynecology 2015. Acta Obstetrica et Gynaecologica Japonica. 2015;67:1803-916 (Japanese).

3. de Boer AG, Verbeek JH, Spelten ER, Uitterhoeve AL, Ansink AC, de Reijke TM, Kammeijer M, Sprangers MA, van Dijk FJ. Work ability and return-towork in cancer patients. Br J Cancer. 2008;98:1342-7.

4. Mehnert A, Koch U. Work satisfaction and quality of life in cancer survivors in the first year after oncological rehabilitation. Work. 2013;46:407-15.

5. Spelten ER, Sprangers MA, Verbeek JH. Factors reported to influence the return to work of cancer survivors: a literature review. Psychooncology. 2002;11:124-31.

6. Maunsell E, Drolet M, Brisson J, Brisson C, Mâsse B, Deschênes L. Work situation after breast cancer: results from a population-based study. J Natl Cancer Inst. 2004;96:1813-22.

7. Bradley CJ, Neumark D, Luo Z, Bednarek H, Schenk M. Employment outcomes of men treated for prostate cancer. J Natl Cancer Inst. 2005;97:958-65.

8. Kennedy F, Haslam C, Munir F, Pryce J. Returning to work following cancer: a qualitative exploratory study into the experience of returning to work following cancer. Eur J Cancer Care (Engl). 2007;16:17-25.

9. Ferrell BR, Grant MM, Funk B, Otis-Green S, Garcia N. Quality of life in breast cancer survivors as identified by focus groups. Psychooncology. 1997;6:13-23.

10. van Muijen P, Weevers NL, Snels IA, Duijts SF, Bruinvels DJ, Schellart AJ, van der Beek AJ. Predictors of return to work and employment in cancer survivors: a systematic review. Eur J Cancer Care (Engl). 2013;22:144-60.

11. Gudbergsson SB, Fosså SD, Sanne B, Dahl AA. A controlled study of job strain in primary-treated cancer patients without metastases. Acta Oncol. 2007:46:534-44.

12. Taskila T, Lindbohm ML. Factors affecting cancer survivors' employment and work ability. Acta Oncol. 2007;46:446-51.

13. Mehnert A. Employment and work-related issues in cancer survivors. Crit Rev Oncol Hematol. 2011;77:109-30. 
14. Bradley CJ, Bednarek HL. Employment patterns of long-term cancer survivors. Psychooncology. 2002;11:188-98.

15. Ahn E, Cho J, Shin DW, Park BW, Ahn SH, Noh DY, Nam SJ, Lee ES, Yun YH. Impact of breast cancer diagnosis and treatment on work-related life and factors affecting them. Breast Cancer Res Treat. 2009;1 16:609-16.

16. Bieri S, Roosnek E, Helg C, Verholen F, Robert D, Chapuis B, Passweg J, Miralbell R, Chalandon Y. Quality of life and social integration after allogeneic hematopoietic SCT. Bone Marrow Transplant. 2008:42:819-27.

17. Hansen JA, Feuerstein M, Calvio LC, Olsen CH. Breast cancer survivors at work. J Occup Environ Med. 2008;50:777-84.

18. Ohguri T, Narai R, Funahashi A, Nishiura C, Yamashita T, Yarita K, Korogi Y. Limitations on work and attendance rates after employees with cancer returned to work at a single manufacturing company in Japan. J Occup Health. 2009;51:267-72.

19. Ito H, Hozawa A, Yamashita H, Kubota I, Nemoto K, Yoshioka T, Kayama T, Murakami M. Employment status among non-retired cancer survivors in Japan. Eur J Cancer Care (Engl). 2015;24:718-23.

20. Islam T, Dahlui M, Majid HA, Nahar AM, Mohd Taib NA, Su TT, MyBCC study group. Factors associated with return to work of breast cancer survivors: a systematic review. BMC Public Health. 2014;14 Suppl 3:S8.

Submit your next manuscript to BioMed Central and we will help you at every step:

- We accept pre-submission inquiries

- Our selector tool helps you to find the most relevant journal

- We provide round the clock customer support

- Convenient online submission

- Thorough peer review

- Inclusion in PubMed and all major indexing services

- Maximum visibility for your research

Submit your manuscript at www.biomedcentral.com/submit

) Biomed Central 